\title{
Hepatocyte growth factor ameliorates acute graft-versus-host disease and promotes hematopoietic function
}

\author{
Takanori Kuroiwa, ${ }^{1}$ Eizo Kakishita, ${ }^{1}$ Teruaki Hamano, ${ }^{1}$ Yasuro Kataoka, ${ }^{1}$ \\ Yoshifumi Seto, ${ }^{1}$ Nobuo Iwata, ${ }^{1}$ Yasufumi Kaneda, ${ }^{3}$ Kunio Matsumoto, ${ }^{4}$ \\ Toshikazu Nakamura, ${ }^{4}$ Takahiro Ueki, ${ }^{2}$ Jiro Fujimoto, ${ }^{2}$ and Tsuyoshi Iwasaki ${ }^{1}$
}

\author{
${ }^{1}$ Second Department of Internal Medicine, and \\ ${ }^{2}$ First Department of Surgery, Hyogo College of Medicine, Nishinomiya, Japan \\ ${ }^{3}$ Division of Gene Therapy Science, and \\ ${ }^{4}$ Division of Biochemistry, Department of Oncology, Biomedical Research Center, \\ Osaka University Graduate School of Medicine, Suita, Japan
}

Address correspondence to: Tsuyoshi Iwasaki, Second Department of Internal Medicine, Hyogo College of Medicine, 1-1 Mukogawa-cho, Nishinomiya, Hyogo 663-8501, Japan.

Phone: 81-79845-6592; Fax: 81-79845-6593; E-mail: tsuyo-i@hyo-med.ac.jp.

Received for publication November 20, 2000, and accepted in revised form April 23, 2001.

Acute graft-versus-host disease (GVHD) is a major complication of bone marrow transplantation (BMT) and is characterized by hematopoietic dysfunction, immunosuppression, and tissue injury in the skin, liver, and intestinal mucosa. Hepatocyte growth factor (HGF), originally identified and cloned as a potent mitogen for hepatocytes, induces mitogenic and antiapoptotic activity in various epithelial cells and promotes hematopoiesis. Working in a murine model of acute GVHD, we performed repeated transfection of the human HGF cDNA into skeletal muscle and showed that this treatment inhibited apoptosis of intestinal epithelial cells and donor T-cell infiltration into the liver, thereby ameliorating the enteropathy and liver injury caused by acute GVHD. HGF also markedly suppressed IFN- $\gamma$ and TNF- $\alpha$ expression in the intestine and liver and decreased the serum IL-12. Furthermore, extramedullary hematopoiesis by donor cells was increased, and the survival rate was improved. These results suggest that HGF may be useful for controlling acute GVHD after allogeneic BMT.

J. Clin. Invest. 107:1365-1373 (2001).

\section{Introduction}

Graft-versus-host disease (GVHD) is a major complication of allogeneic bone marrow transplantation (BMT) that is initiated by contaminating $\mathrm{T}$ cells in the bone marrow (1). Acute GVHD is characterized by hematopoietic dysfunction, immunosuppression, and tissue injury that affects the skin, liver, and intestinal mucosa (2-4). To prevent GVHD, most therapies have focused on the elimination of donor $T$ cells from the graft or the use of nonspecific immunosuppressive drugs. Unfortunately, these approaches can result in poor engraftment and impaired immune reconstitution (5). An alternative approach to the prevention of GVHD is to prevent tissue damage and the subsequent inflammatory response in the early period after the onset of GVHD. Gastrointestinal (GI) tract injury is critical for the subsequent development of systemic GVHD because it contributes to the entry of endotoxins from the gut lumen into the systemic circulation, resulting in an increase of inflammatory cytokine production by macrophages (6). Also, clearance of endotoxins is decreased by liver injury, resulting in amplification of the manifestations of GVHD (7). Thus, GI tract and hepatic injury, together with an increased circulating endotoxin level, lead to an increase in the morbidity and mortality of GVHD.
Hepatocyte growth factor (HGF) was originally identified and cloned as a potent mitogen for hepatocytes $(8,9)$. It has mitogenic, motogenic, and morphogenic effects on various epithelial tissues as well as the liver (particularly), the kidneys, lungs, and intestines (10-12). HGF also shows antiapoptotic activity (13) and plays a role in enhancing hematopoiesis (14). Intravenous injection of recombinant human HGF (rHGF) has been shown to enhance liver and kidney regeneration in mice, as well as prevent acute renal failure and suppress the onset of liver cirrhosis induced by dimethylnitrosamine (10, $15)$, suggesting that HGF plays an important role in the tissue-repair process. The present study was performed using a murine model of acute GVHD induced in $(\mathrm{B} 6 \times \mathrm{DBA} / 2) \mathrm{F}_{1}\left(\mathrm{BDF}_{1}\right)$ mice by grafts from C57BL/6 (B6) parental mice. Repeated transfection of the human HGF gene into skeletal muscle was found to inhibit enteropathy and liver injury caused by acute GVHD, thereby improving the survival rate of the mice. Furthermore, an increase of extramedullary hematopoiesis by donor cells in the spleen and liver was observed after HGF gene transfer. These results suggest that HGF gene therapy may be useful to control acute GVHD after allogeneic BMT. 


\section{Methods}

Animals. C57BL/6 (B6, H-2 $\left.{ }^{\mathrm{b}}\right)$ mice were used as donors and $(\mathrm{B} 6 \times \mathrm{DBA} / 2) \mathrm{F}_{1}\left(\mathrm{BDF}_{1}, \mathrm{H}-2^{\mathrm{b}-\mathrm{d}}\right)$ mice were used as recipients. All mice were $8-12$ weeks old and were purchased from Shizuoka Laboratory Animal Center (Shizuoka, Japan). The mice were maintained in a pathogen-free mouse facility at The Hyogo College of Medicine. Animal care was in accordance with the guidelines of The Hyogo College of Medicine.

Induction of GVHD. Nonlethal GVHD was induced as described previously (16). Briefly, $10^{8}$ spleen cells harvested from $\mathrm{B} 6$ donors were injected into the tail veins of recipient $\mathrm{BDF}_{1}$ mice (Figure 1a, upper). For the induction of lethal GVHD, recipient mice were exposed to $900 \mathrm{cGy}$ of total body irradiation (TBI) from an $\mathrm{x}$-ray source at a dose rate of $50 \mathrm{cGy} / \mathrm{min}$, after which bone marrow cells $\left(5 \times 10^{6}\right)$ plus spleen cells $\left(2 \times 10^{7}\right)$ from B6 donors were injected via the tail veins (Figure 1a, lower). Recipient $\mathrm{BDF}_{1}$ mice injected with syngeneic bone marrow cells $\left(5 \times 10^{6}\right)$ after TBI were used as BMT controls.

Expression vector and preparation of liposomes containing bemagglutinating virus of Japan liposomes). Human HGF cDNA $(2.2 \mathrm{~kb})$ was inserted into the EcoRI and NotI sites of the PUC-SR $\alpha$ expression vector plasmid under the control of the SR $\alpha$ promoter (17). Hemagglutinating virus of Japan (HVJ) liposomes containing plasmid DNA and high-mobility group 1 (HMG-1) were constructed as described previously (18).

Briefly, phosphatidylserine, phosphatidylcholine, and cholesterol were mixed at a weight ratio of 1:4.8:2. This lipid mixture $(1 \mathrm{mg})$ and plasmid DNA (20-40 $\mu \mathrm{g})$, which was complexed previously with 6-12 $\mu$ g of HMG-1 nonhistone chromosomal protein purified from calf thymus, were sonicated to form liposomes and then mixed with ultravioletirradiated (UV-irradiated) HVJ. Free virus was subsequently removed from the HVJ liposomes by sucrose density-gradient centrifugation.

Gene transfer into mouse skeletal muscle and experimental design. From the time of induction of GVHD, $\mathrm{BDF}_{1}$ mice were injected into the gluteal muscles with either HVJ liposomes containing $8 \mu \mathrm{g}$ of human HGF expression vector (HGF-HVJ liposomes) or with PBS (GVHD control). BMT controls were also injected with HGFHVJ liposomes or PBS from the time of BMT. Gene transfer was repeated once a week after induction of GVHD (Figure 1a).

Histopathology. Tissues were fixed in $10 \%$ buffered formalin and embedded in paraffin. Sections were stained with hematoxylin and eosin and were examined by light microscopy. To detect apoptosis in intestinal sections, a modified terminal deoxynucleotidyl transferase-mediated dUTP nick-end labeling (TUNEL) method was applied using the Apo Tag In Situ Apoptosis Detection System (Oncor Inc., Gaithersburg, Maryland, USA) (19).

Preparation of liver lymphocytes. Mouse hepatic mononuclear cells were prepared as described previously (20). Briefly, livers were harvested from mice and were minced, passed through a mesh, and suspended in PBS. To remove hepatic parenchymal cells, the cells were resuspended in 33\% Percoll containing $100 \mathrm{U} / \mathrm{ml}$ heparin and were centrifuged at $800 \mathrm{~g}$ for 10 minutes at room temperature. The pellet was resuspended in red blood cell (RBC) lysis solution and then washed three times in PBS.

Flow cytometry. Cell suspensions were prepared in PBS containing $1 \%$ FCS and $0.1 \%$ sodium azide. The cells were incubated with an anti-Fc receptor $\mathrm{mAb}(2.4 \mathrm{G} 2)$ for 10 minutes at $4^{\circ} \mathrm{C}$ and then incubated with a FITCconjugated $\mathrm{mAb}$ and a phycoerythrin-conjugated (PEconjugated) $\mathrm{mAb}$ for 30 minutes. The stained cells were washed twice, resuspended, and analyzed using a FACScan (Becton Dickinson, Mountain View, California, USA). The anti-Fc receptor (2.4G2) mAb, FITC-conjugated anti-mouse $\mathrm{H}-2 \mathrm{~K}^{\mathrm{b}}$ (clone AF6-88.5) mAb, antimouse CD3 (clone 145-2C11) mAb, anti-Gr-1 (clone $\mathrm{RB} 6-8 \mathrm{C5}$ ) $\mathrm{mAb}$, and PE-conjugated anti-mouse $\mathrm{H}-2 \mathrm{~K}^{\mathrm{d}}$ (clone SF1-1.1) $\mathrm{mAb}$ were purchased from PharMingen (San Diego, California, USA). Multicolor flow cytometry was performed as described previously, with some modifications (16). Channel numbers for the integration of data were chosen on the basis of the staining pattern of normal spleen cells. Staining of normal $F_{1}$ spleen cells with anti-MHC Ab's gave a unimodal-positive profile when compared with the negative controls. When donor parental cells were detected in the GVHD mice, these cells were identified as subpopulations that were clearly negative (equivalent to nonspecific findings) for $\mathrm{F}_{1}$-specific $\mathrm{MHC}$ markers.

Quantitative RT-PCR. Total RNA was extracted from the liver, intestine, and thymus using the standard guanidine thiocyanate-phenol chloroform method. After quantification of the isolated RNA using spectrophotometry, $1 \mu \mathrm{g}$ of total RNA was reverse transcribed in the presence of random hexanucleotide primers (Promega Corp., Madison, Wisconsin, USA) and avian myeloblastosis virus reverse transcriptase (Promega Corp.). The reaction mixture was incubated at $42^{\circ} \mathrm{C}$ for 1 hour and then at $72^{\circ} \mathrm{C}$ for 5 minutes to terminate the reaction. An aliquot (one-tenth) of this reaction mixture was amplified by PCR to generate mouse IFN- $\gamma$, TNF- $\alpha$, and $\beta$-actin cDNAs. The PCR reaction mixture contained $50 \mathrm{pmol}$ of each primer, 25 mM dATP, dGTP, dCTP, and dTTP (Amersham Pharmacia Biotech Corp., Buckinghamshire, United Kingdom), $2 \mathrm{mM}$ of $10 \times$ reaction buffer, $1 \mathrm{U}$ of Taq DNA polymerase (Roche Diagnostics GmbH, Mannheim, Germany), and sterile distilled water. Amplification was performed at $94^{\circ} \mathrm{C}$ for 1 minute, $65^{\circ} \mathrm{C}$ for 1 minute, and $72^{\circ} \mathrm{C}$ for 1 minute in a DNA thermal cycler (Perkin Elmer Cetus Instruments, Norwalk, Connecticut, USA) for 26, 29, and 32 cycles to ensure linearity. Then a $10-\mu l$ aliquot of the reaction mixture was subjected to electrophoresis on $1.5 \%$ agarose gel (NuSieve; FMC Corp., Vallensbaek Strand, Denmark) containing ethidium bromide, and the gel was photographed under UV light. The $5^{\prime}$ and $3^{\prime}$ PCR 
primers were obtained from CLONTECH Laboratories Inc. (Palo Alto, California, USA) and Bex (Tokyo, Japan), respectively, and had the following sequences: TNF- $\alpha, \quad 5^{\prime}$-TTCTGTCTACTGAACTTCGGGGTGATCGGTCC- $3^{\prime}$ and $5^{\prime}$-GTATGAGATAGCAAATCGGCTGACGGTGTGGG- $3^{\prime} ; \quad$ IFN- $\gamma, \quad 5^{\prime}$-TGGCTGTTTCTGGCTGTTACTG- $3^{\prime}$ and $5^{\prime}$-AATCAGCAGCGACTCCTTTTCC-3'; $\beta$-actin, $5^{\prime}$-TGTGATGGTGGGAATGGGTCAG- $3^{\prime}$ and $5^{\prime}$ TTTGATGTCACGCACGATTTCC- $3^{\prime}$. The IFN- $\gamma$ and TNF- $\alpha$ PCR products were normalized in relation to the $\beta$-actin internal control.

ELISA for HGF and IL-12. The human HGF level in serum was measured by ELISA using an anti-human HGF mAb, and the serum level of mouse HGF was measured by ELISA using an anti-mouse HGF mAb (Institute of Immunology, Tokyo, Japan). The human HGF ELISA system specifically detected human HGF, but not mouse HGF. The mouse IL-12 level in serum was measured by ELISA using an anti-mouse IL-12 $\mathrm{mAb}$ (Genzyme Pharmaceuticals, Cambridge, Massachusetts, USA). Each assay was performed according to the manufacturer's protocol.
Peripheral blood cell counts. Blood samples were obtained by cardiac puncture under ether anesthesia. Samples were analyzed using an automated hematology analyzer (SE 9000; Sysmex, Kobe, Japan).

Statistical analysis. Group mean values were compared using the two-tailed Student's $t$ test. Survival data were plotted by the Kaplan-Meier method and were analyzed by the log-rank test. A $P$ value less than 0.05 was considered significant.

\section{Results}

Effect of HGF on intestinal injury. We reported previously that repeated transfection of the human HGF gene into skeletal muscle resulted in a sustained high serum level of human as well as endogenous rat HGF (18). After a single injection of HVJ liposomes and 8 $\mu \mathrm{g}$ of the human HGF expression vector (HGF-HVJ liposomes), substantial amounts of human as well as mouse HGF were detected by ELISA in the serum of mice. The total level of HGF (human and mouse $\mathrm{HGF}$ ) in the plasma was $0.20 \mathrm{ng} / \mathrm{ml}$ before injection, $1.07 \mathrm{ng} / \mathrm{ml} 1$ day after injection, $1.35 \mathrm{ng} / \mathrm{ml} 4$ days
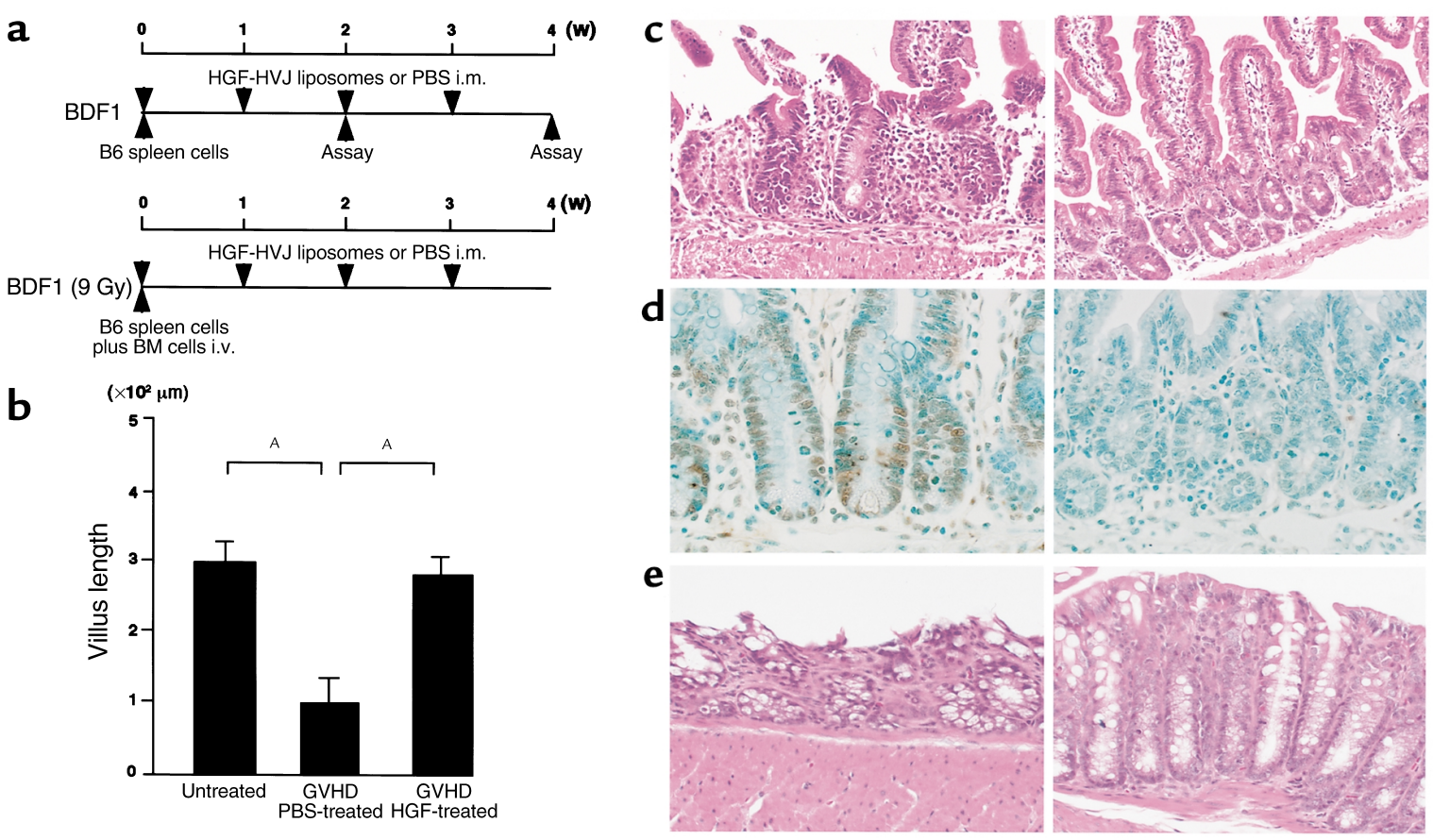

Figure 1

Experimental protocol and effect of HGF on intestinal injury. (a) Schedule for induction of GVHD and injection of HGF-HVJ liposomes or PBS. Top: Nonlethal GVHD model. GVHD was induced by injection of $10^{8}$ spleen cells harvested from B6 donors into nonirradiated BDF 1 mice. From the time of GVHD induction, Gluteal muscles of $\mathrm{BDF}_{1}$ mice were injected either with HVJ liposomes containing $8 \mu \mathrm{g}$ of human HGF expression vector (HGF-HVJ liposomes) or with PBS (GVHD control). Gene transfer was repeated once a week after GVHD induction. Bottom: Lethal GVHD model. For the induction of lethal GVHD, recipient BDF 1 mice were exposed to $900 \mathrm{cGy}$ of TBI, and bone marrow cells $\left(5 \times 10^{6}\right)$ plus spleen cells $\left(2 \times 10^{7}\right)$ from B6 donors were injected. HGF gene transfer was repeated once a week for 3 weeks after induction of GVHD. i.m., intramuscularly; i.v., intravenously. (b) Nonirradiated BDF ${ }_{1}$ mice were injected intravenously with $10^{8}$ spleen cells from B6 mice. HGF-HVJ liposomes $(8 \mu \mathrm{g})$ were administered intramuscularly on day 0 and day 7 after induction of GVHD. Animals were sacrificed after 2 weeks of GVHD, and the intestines were removed. The length of villi in the small intestine was measured using a calibrated lens to study at least 15-20 complete and straight villi per slide in five untreated control mice, five GVHD control mice injected with PBS, and five GVHD mice injected with HGF-HVJ liposomes. Data represent the mean \pm SD of five mice. ${ }^{A} P<0.05$. (c) Hematoxylin and eosin staining of the small intestine in GVHD mice with or without HGF gene therapy. $\times 200$. (d) Apoptosis of small intestinal epithelial cells. The TUNEL method was used to detect apoptotic cells. $\times 200$. (e) Hematoxylin and eosin staining of the large intestine. $\times 200$. 


\section{Figure 2}

Effect of HGF on liver injury. (a) Hematoxylin and eosin staining of liver sections from GVHD mice with or without HGF gene transduction 2 weeks after induction of GVHD. Liver tissue from GVHD control mice showed cellular infiltration in the periportal area (arrow). $\times 100$. (b) Hematoxylin and eosin staining of liver sections from GVHD mice without HGF gene transduction at 2 weeks after induction of GVHD. $\times 400$. (c) Effect of HGF gene transduction on intrahepatic infiltration of mononuclear cells and donor T cells. Liver-infiltrating mononuclear cells were obtained from untreated mice and GVHD mice with or without HGF gene transduction. The number of donor-derived T cells was determined by multiplying the total mononuclear cell count by the $\mathrm{H}-2 \mathrm{~K}^{\mathrm{d}}$-negative and $\mathrm{CD} 3$-positive populations. Data are the mean \pm SD of five mice. ${ }^{A} P<0.05$.

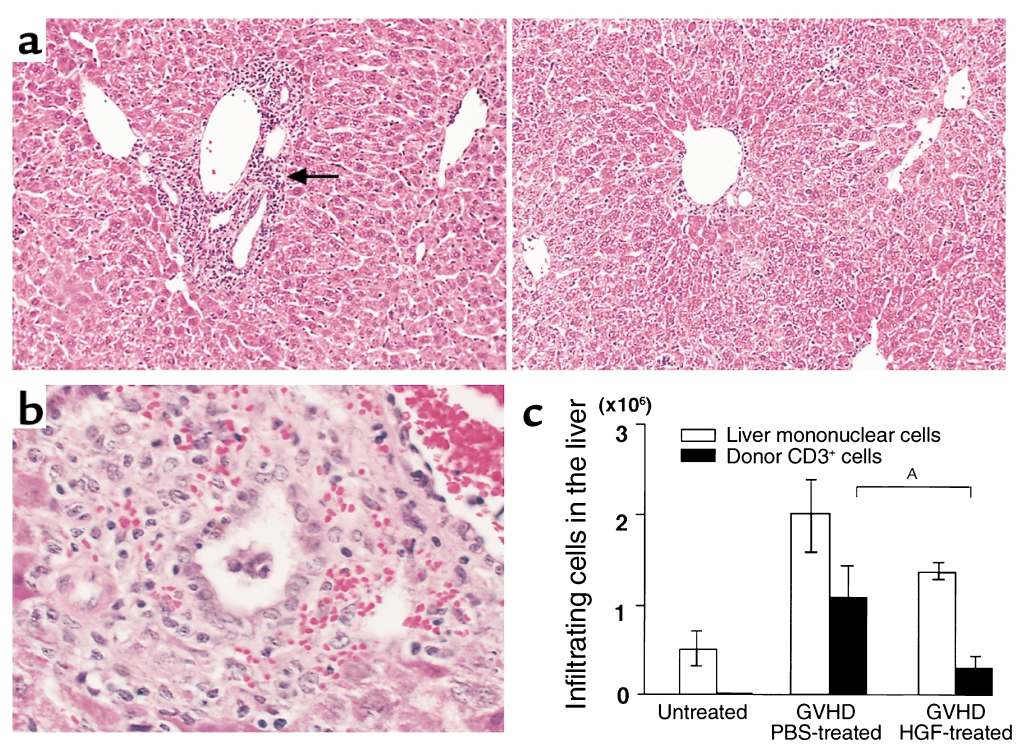

after injection, and $1.13 \mathrm{ng} / \mathrm{ml} 7$ days after injection. Since HGF has potent cytoprotective and antiapoptotic actions (10-13) and c-Met/HGF receptors are expressed on various epithelial cells (21), we hypothesized that HGF may protect the GI tract epithelium from damage caused by GVHD. We used a nonlethal parent-to- $\mathrm{F}_{1}$ GVHD model to address this issue because this model is useful for studying target organ injury caused by GVHD in the intestine, liver, thymus, and bone marrow. From the time of parental B6 spleen-cell transfer, $\mathrm{BDF}_{1}$ mice were injected into the gluteal muscles once a week with either HGF-HVJ liposomes or PBS (GVHD control), and intestinal histopathology was examined 2 weeks after the onset of GVHD (Figure 1a, upper). HVJ liposomes containing a mock vector had the same effect as injection of PBS (data not shown). Injection of the HGF gene largely prevented the changes of intestinal morphology observed in GVHD control mice, such as atrophy of the villi, infiltration of lymphocytes, and destruction of crypts in the small intestine (Figure 1c, left). In the GVHD control mice the average villus length was significantly decreased (Figure 1b). The majority of these changes were inhibited by HGF treatment (Figure 1c, right; Figure 1b). Intestinal damage in GVHD is known to be caused by apoptosis of epithelial cells, which occurs exclusively in the crypt area within the stem-cell zone during the destructive phase of GVHD (22). We investigated whether HGF

Figure 3 gene transfer inhibited apoptosis of small bowel epithelial cells by in situ TUNEL staining. Apoptotic cells were found in the crypt area of GVHD mice (Figure 1d, left), while HGF treatment inhibited such apoptosis (Figure 1d, right). Histological changes of the large intestine, such as mucosal and submucosal cell infiltration, crypt destruction, and loss of goblet cells (Figure 1e, left), were also inhibited by HGF treatment (Figure 1e, right).

Effect of HGF on liver injury. Hepatic GVHD is characterized by the development of portal hepatitis, endothelialitis, and progression to nonsuppurative destructive cholangitis (NSDC) (23). Expansion of the portal tracts by cellular infiltration was one of the ear-
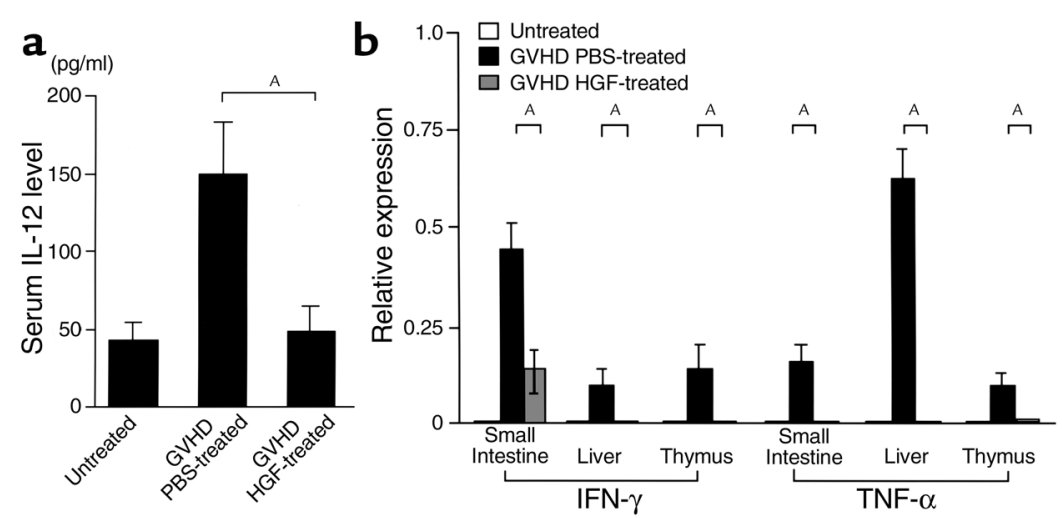

Effect of HGF on the inflammatory cytokine cascade. (a) IL-12 levels in serum from untreated and GVHD mice with or without HGF gene therapy. Serum was obtained 2 weeks after the induction of GVHD. Data represent the mean \pm SD of five mice. ${ }^{A} P<0.05$. (b) IFN- $\gamma$ and TNF- $\alpha$ mRNA expression in the small intestine, liver, and thymus. Total RNA was isolated from tissue samples of the small intestine, liver, and thymus that were harvested from untreated mice and GVHD mice with or without HGF gene therapy 2 weeks after the induction of GVHD. The CDNAs were generated by RT-PCR and were amplified using primers specific for IFN- $\gamma$, TNF- $\alpha$, and the housekeeping gene $\beta$-actin. The amounts of IFN- $\gamma$ and TNF- $\alpha$ mRNA were normalized for that of $\beta$-actin. Expression of cytokine mRNA is shown relative to $\beta$-actin, and data represent the mean \pm SD of 5 mice. ${ }^{A} P<0.05$. 

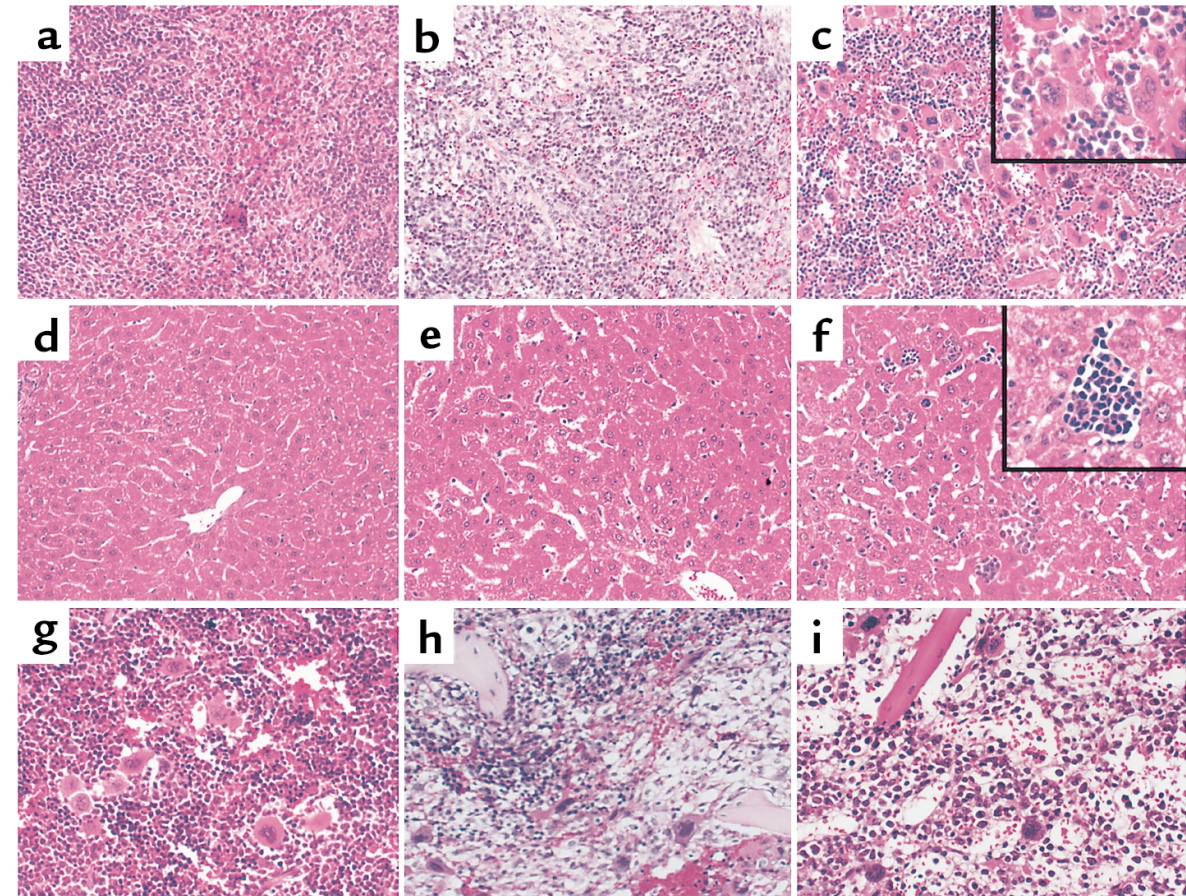

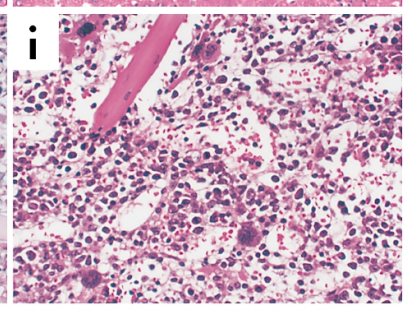

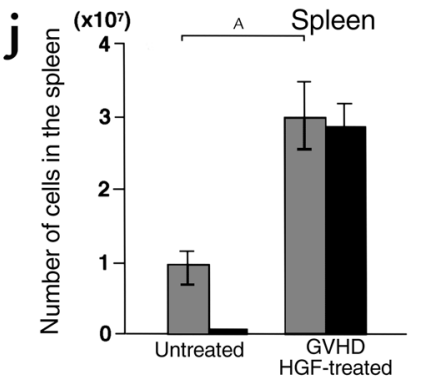

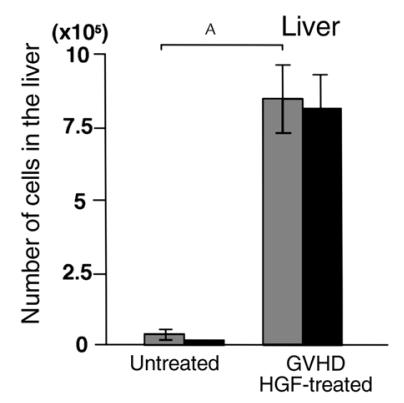

$\square$ Total Gr-1+ cells

Donor Gr-1+ cells

\section{Figure 4}

Extramedullary hematopoiesis in GVHD mice. (a-i) Histopathological examination was performed using hematoxylin and eosin-stained slides of tissue samples from the spleen $(\mathbf{a}-\mathbf{c})$, liver $(\mathbf{d}-\mathbf{f})$, and bone marrow $(\mathbf{g}-\mathbf{i})$ obtained from untreated mice $(\mathbf{a}, \mathbf{d}, \mathbf{g})$, PBS-treated GVHD mice (b, e, h), and HGF-treated GVHD mice $(\mathbf{c}, \mathbf{f}, \mathbf{i}) 4$ weeks after the induction of GVHD. Spleen tissue from HGF-treated GVHD mice showed marked extramedullary hematopoiesis along with numerous megakaryocytes. Liver tissue from HGF-treated GVHD mice showed numerous hematopoietic foci containing granulocyte precursor cells and erythroblasts. $\times 200$; inset, $\times 400$. (j) Spleen cells and liverinfiltrating mononuclear cells were obtained from untreated mice and HGF-treated GVHD mice. The number of donor-derived granulocytes was determined by multiplying the total mononuclear cell count by the $\mathrm{H}-2 \mathrm{~K}^{\mathrm{d}}$-negative and $\mathrm{Gr}$-1-positive populations. Data represent the mean \pm SD of five mice. $P<0.05$.

liest abnormalities to be seen in the present model, and it occurred concomitantly with the onset of transient acute liver failure. The inflammatory cell infiltrates in the liver were composed mainly of $\mathrm{T}$ cells, which are known to induce hepatic injury and bile duct destruction by various mechanisms, such as the Fas-Fas ligand (L) and TNF-TNF receptor (R) pathways $(7,24)$. In GVHD control mice, the liver showed cellular infiltration in the periportal area (Figure 2a, left) and NSDC at 2 weeks after the onset of GVHD (Figure 2b). The mice treated with HGF showed less cellular infiltration and fewer NSDC lesions when compared with GVHD control mice (Figure 2a, right). Since donor T cells contribute to the development of hepatic lesions in GVHD, we analyzed the surface expression of donor CD3 using flow cytometry. The total number of donor $\mathrm{T}$ cells was calculated by multiplying the total number of mononuclear cells in the liver by the $\mathrm{H}-2 \mathrm{~K}^{\mathrm{d}}$-negative and CD3-positive populations. The total number of hepatic mononuclear cells was markedly increased from $0.5 \times 10^{6}$ to $2.0 \times 10^{6}$ after 2 weeks of GVHD. HGF treatment decreased the total number of hepatic mononuclear cells from $2.0 \times 10^{6}$ to $1.4 \times 10^{6}$ cells at 2 weeks, and it significantly decreased the number of donor $\mathrm{T}$ cells from $1.1 \times 10^{6}$ to $0.3 \times 10^{6}$ cells per liver (Figure 2c). These results indicate that HGF treatment inhibited donor T-cell infiltration into the liver and subsequent hepatic injury.

Effect of HGF on the inflammatory cytokine cascade. IL-12 is known to be a critical cytokine in the induction of Th1 responses (25), and the Th1 cytokine IFN- $\gamma$ primes macrophages to secrete inflammatory cytokines after stimulation by endotoxin (26). The importance of the inflammatory cytokine cascade in the pathogenesis of both clinical and experimental GVHD is now well accepted $(4,6)$. The serum level of IL-12 was significantly decreased by HGF treatment (Figure 3a). We next examined the effect of HGF treatment on IFN- $\gamma$ and TNF- $\alpha$ mRNA expression in some target organs of GVHD. Total RNA was isolated from the liver, small intestine, and thymus, and quantitative RT-PCR was performed. IFN- $\gamma$ and TNF- $\alpha$ mRNA were not expressed in the liver, small intestine, and thymus of normal mice, but were strongly induced at 2 weeks after the onset of GVHD. HGF treatment strongly suppressed IFN- $\gamma$ and TNF- $\alpha$ mRNA expression in these organs (Figure $3 \mathrm{~b}$ ). Effect of HGF on extramedullary hematopoiesis. During weeks 3-5 of GVHD, the greatest decrease of host hematopoietic cells occurs in this mouse model. After the loss of host hematopoietic cells, the spleens of GVHD mice are initially repopulated by engrafted donor hematopoietic stem cells derived from the inject- 

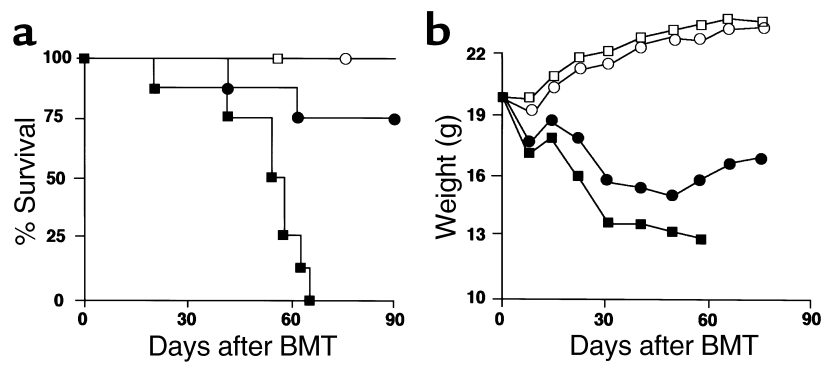

Figure 5

HGF caused a reduction of mortality (a) and weight loss (b) in a lethal GVHD model. Recipients were transplanted with $5 \times 10^{6}$ bone marrow cells plus $2 \times 10^{7}$ spleen cells from allogeneic (B6) donors after 9 Gy of TBI. Recipients transplanted with $5 \times 10^{6}$ bone marrow cells from syngeneic $\left(\mathrm{BDF}_{1}\right)$ donors after $\mathrm{TBI}$ were used as $\mathrm{BMT}$ controls. HGF-HVJ liposomes (or PBS) were injected on day $0,7,14$, and 21. PBS-treated syngeneic BMT (open squares; $n=4$ ), HGF-treated syngeneic BMT (open circles; $n=4$ ), PBS-treated GVHD (filled squares; $n=8$ ), and HGF-treated GVHD (filled circles; $n=8$ ) are indicated. $P<0.01$ for survival after PBS injection versus HGF-HVJ liposomes injection and $P<0.05$ for body weight from 4 weeks after BMT with PBS versus HGF-HVJ liposomes. Representative data from three similar experiments are shown.

ed spleen cells in week 4 of GVHD (16). Four weeks after the onset of GVHD, we found that the spleens of HGF-treated mice were twice as large as those of GVHD control mice, and this enlargement was caused by marked extramedullary hematopoiesis along with numerous megakaryocytosis (Figure 4c). Liver tissue from HGF-treated mice also showed numerous hematopoietic foci containing granulocyte precursor cells and erythroblasts (Figure 4f). However, bone marrow tissue from HGF-treated mice was hypoplastic, and no difference in hematopoiesis was observed between HGF-treated and GVHD control mice (Figure $4, \mathrm{~h}$ and i). To determine whether the increase of hematopoiesis in the spleen and liver reflected the activity of donor cells, we analyzed surface expression of donor Gr-1 by flow cytometry and calculated the number of donor granulocytes by multiplying the total number of mononuclear cells in the spleen and liver by the $\mathrm{H}-2 \mathrm{~K}^{\mathrm{d}}$-negative and $\mathrm{Gr}-1$-positive populations. It was found that the granulocytes in the spleens and livers of HGF-treated mice were exclusively of donor origin (Figure 4j). These results suggest that HGF promoted hematopoiesis by donor cells in GVHD mice.

Effect of HGF on mortality, morbidity, and hematopoiesis in a lethal GVHD model. To determine whether HGF treatment could improve survival and decrease the morbidity of acute GVHD, experiments were performed using a lethal GVHD model. Lethal GVHD was induced by infusion of $5 \times 10^{6}$ bone marrow cells plus $2 \times 10^{7}$ spleen cells from $\mathrm{B} 6$ mice into irradiated $\mathrm{BDF}_{1}$ mice. At the start of GVHD induction, the HGF expression vector or PBS (GVHD control) was injected into the recipient mice once a week for 3 weeks (Figure 1a, lower).

Although all GVHD control mice died within 65 days after BMT, mice receiving HGF exhibited a much higher survival rate (Figure 5a). HGF treatment had no significant effect on the body weights of the recipients for 4 weeks after the induction of GVHD, but it prevented subsequent weight loss in the surviving mice (Figure $5 b$ ).

Since HGF treatment induced extramedullary hematopoiesis by donor cells in the nonlethal GVHD model (Figure 4), we next examined whether it could enhance hematopoiesis in the lethal GVHD model. On day 60 after induction of lethal GVHD, we examined the peripheral blood and the cellularity in the spleen, bone marrow, and thymus. Peripheral blood cells were significantly decreased in GVHD control mice, whereas HGF treatment markedly ameliorated the hematological dysfunction caused by GVHD. The spleen and thymus were both smaller in GVHD control mice than in HGF-treated mice, and the cellularity of the spleen, bone marrow, and thymus was markedly increased in HGF-treated compared with control mice (Figure 6).

\section{Figure 6}

Augmentation of hematopoietic function by HGF in a lethal GVHD model. Recipients were transplanted with $5 \times 10^{6}$ bone marrow cells plus $2 \times 10^{7}$ spleen cells from allogeneic (B6) donors after 9 Gy of TBI. Recipients transplanted with $5 \times 10^{6}$ bone marrow cells from syngeneic $\left(\mathrm{BDF}_{1}\right)$ donors after TBI were used as BMT controls. HGF-HVJ liposomes (or PBS) were injected on day $0,7,14$, and 21 . Sixty days after the induction of lethal GVHD, the peripheral blood cell profile, as well as the number of spleen cells, bone marrow cells, and thymus cells, was determined. Data represent the mean \pm SD of five mice. ${ }^{A} P<0.05$. Similar results were obtained in two additional experiments.
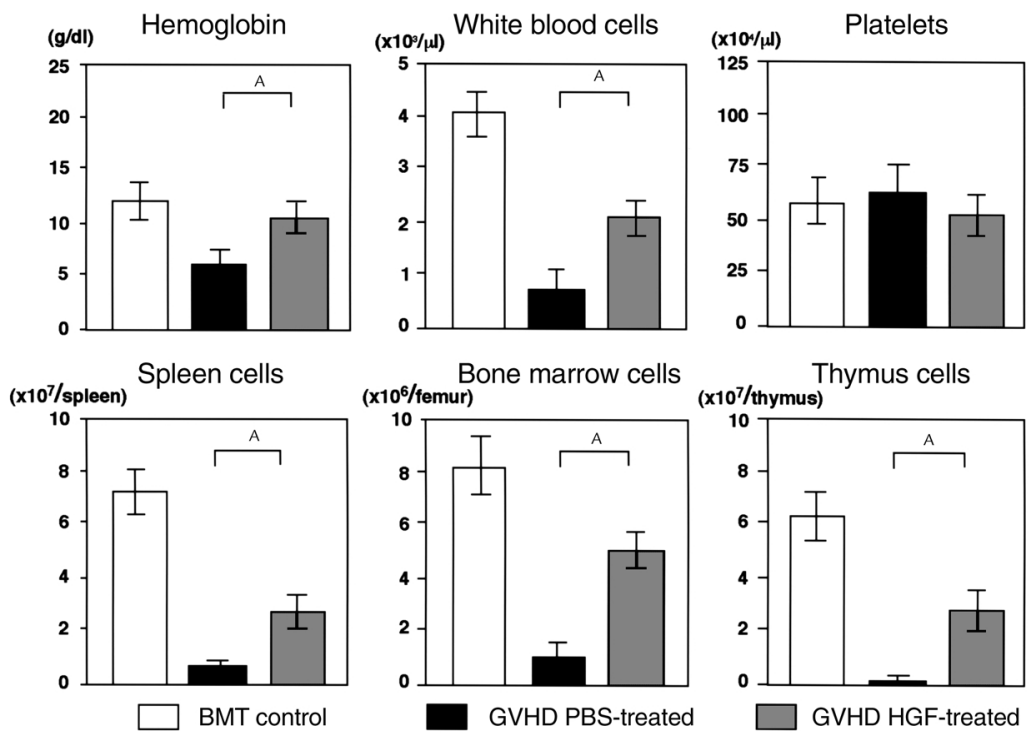

Thymus cells

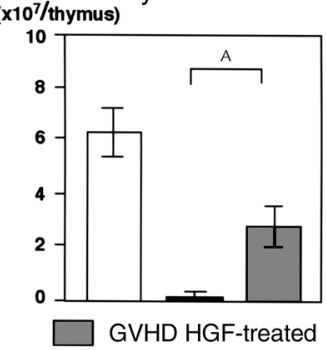


a
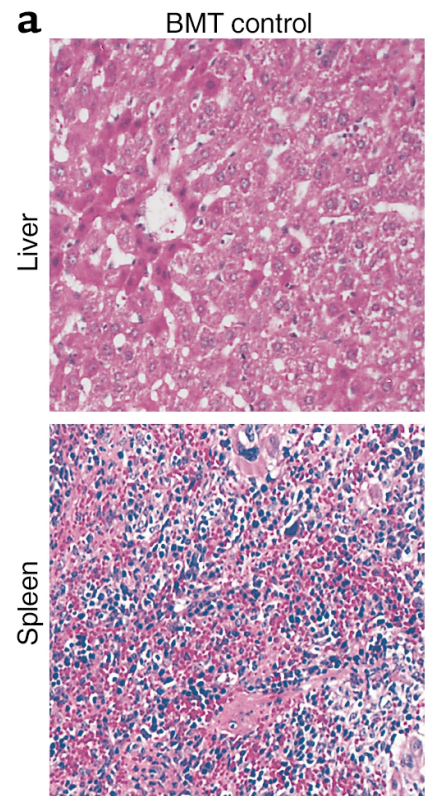

BMT HGF-treated
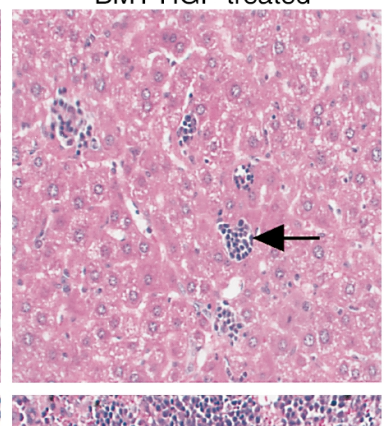

b

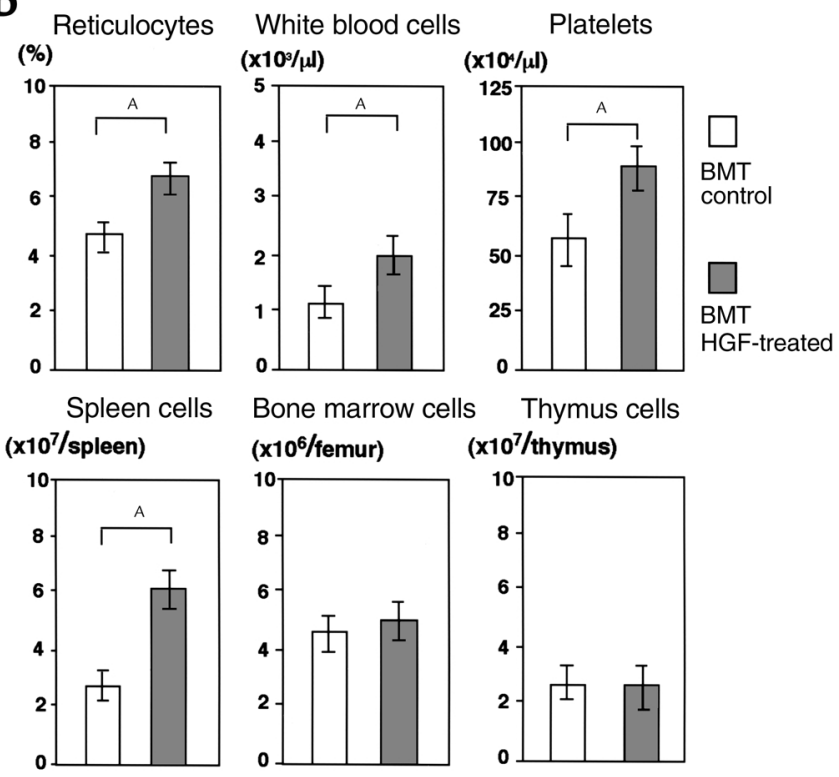

Figure 7

Augmentation of hematopoietic function by HGF in a syngeneic BMT model. Recipients were transplanted with $5 \times 10^{6}$ bone marrow cells from syngeneic $\left(\mathrm{BDF}_{1}\right)$ donors after 9 Gy of TBI. HGF-HVJ liposomes (or PBS) were injected on days 0 and 7. Ten days after BMT, histological examination was performed (a), and the peripheral blood cell profile, as well as the number of spleen cells, bone marrow cells, and thymus cells (b), was determined. (a) Hematoxylin and eosin staining of the liver and spleen in syngeneic BMT mice with or without HGF gene transduction. Liver tissue from HGF-treated GVHD mice showed hematopoietic foci containing granulocyte precursor cells and erythroblasts (arrow). Spleen tissue from HGF-treated GVHD mice showed marked extramedullary hematopoiesis along with numerous megakaryocytes (arrow). $\times 200$. (b) The peripheral blood cell profile and the number of spleen cells, bone marrow cells, and thymus cells are shown as the mean \pm SD of four mice. ${ }^{A} P<0.05$.

To determine whether enhanced hematopoiesis was due to an independent effect of HGF on hematopoietic function or was an indirect effect secondary to the amelioration of GVHD, we examined the effect of HGF treatment on hematopoiesis in a syngeneic BMT model. HGF induced extramedullary hematopoiesis in the liver and spleen (Figure 7a) and increased circulating reticulocytes, suggesting the occurrence of erythroid cell proliferation (Figure 7b). HGF treatment also promoted the recovery of circulating white blood cells and platelets and increased the cellularity of the spleen (Figure 7b). These results indicated that HGF gene therapy could promote hematopoiesis independently of its effect on GVHD in mice with lethal GVHD.

\section{Discussion}

The inflammatory cytokine cascade involving IL-12, IFN- $\gamma$, and TNF- $\alpha$ mediates tissue injury in GVHD. IL-12 is known to be a critical cytokine for the induction of Th1 responses in GVHD, and blocking IL-12 production during BMT is sufficient to reduce GVHD (27). GI tract epithelial damage is induced initially by alloreactive donor $\mathrm{T}$ cells, and this allows endotoxin from the gut lumen to enter the mucosal and submucosal tissues as well as the systemic circulation (6). Macrophages activated by endotoxin secrete IL-12, which in turn stimulates T cells to produce IFN- $\gamma(25)$. In addition, IFN- $\gamma$ potentiates the production of IL-12 by macrophages exposed to endotoxin (28). Therefore, there appears to be positive feedback interaction between $T$ cells and macrophages that leads to high levels of IFN- $\gamma$ and IL-12 in the organs damaged by GVHD. Suppression of the plasma IL-12 level in GVHD mice by HGF treatment suggests that HGF prevented GI injury by an antiapoptotic effect on intestinal epithelial cells and that it blocked the feedback induction of IL-12, presumably by inhibiting the entry of endotoxin into the systemic circulation. Macrophages primed by IFN- $\gamma$ from donor T cells can secrete a large amount of TNF- $\alpha$ after stimulation by endotoxin, which then mediates GI injury $(6,24)$. Suppression of IFN- $\gamma$ and TNF- $\alpha$ mRNA expression in the small intestine of HGF-treated GVHD mice was most likely achieved through inhibition of the cytokine cascade by protecting the GI epithelium from GVHD injury. Th1 and inflammatory cytokines are also important for the pathogenesis of liver injury, since IFN- $\gamma$ and TNF- $\alpha$ augment the expression of MHC class I molecules and intercellular adhesion molecule I on endothelial cells and bile duct epithelial cells, thereby inducing the recruitment of effector cells into the liver. In addition, Kupffer cells activated by endotoxin secrete TNF- $\alpha$, which activates the signal transduction pathway toward apoptosis in hepatocytes (7). This study demonstrated that HGF gene administration restricted the migration of donor $\mathrm{T}$ cells into the liver and reduced the extent of histopathological damage. It also downregulated the expression of IFN- $\gamma$ and 
TNF- $\alpha$ mRNA in the liver. These results suggest that the number of infiltrating donor $\mathrm{T}$ cells is correlated with the histopathological severity of GVHD, as well as with Th1 and inflammatory cytokine expression in the liver, and that HGF diminishes the infiltration of donor $\mathrm{T}$ cells into the liver. Translocation of endotoxin from the gut lumen into the portal circulation probably leads to endotoxin accumulation in the liver and augments the induction of TNF- $\alpha$ production by Kupffer cells. Endotoxin and TNF- $\alpha$ could then stimulate donor $\mathrm{T}$ cells to proliferate and expand in the liver (29). Thus, inhibition of endotoxin translocation into the portal circulation by preventing GI tract injury through HGF treatment possibly results in the inhibition of donor T-cell expansion in the liver.

Graft rejection and GVHD represent two potentially lethal immunological side effects of allogeneic BMT between genetically nonidentical individuals. GVHD inhibits donor hematopoietic cell engraftment by immune mechanisms (30). One approach to the prevention of fatal GVHD is removal of immunocompetent $\mathrm{T}$ cells in allogeneic BMT, but this results in an increased frequency of graft rejection due to the response of host immune cells against donor stem cells (5). Thus, effective donor hematopoietic cell engraftment is important for the treatment of GVHD. Following the loss of host hematopoietic cells during the cytotoxic phase of GVHD, donor hematopoietic cells derived from injected spleen cells appear in the spleen after 4 weeks in the nonlethal GVHD model (16). We observed extramedullary hematopoiesis derived from donor hematopoietic stem cells in the livers and spleens of HGF-treated GVHD mice, which suggested an increase of hematopoietic function as a result of HGF therapy. HGF augments the growth of hematopoietic progenitor cells (14), and the liver can provide an environment for extramedullary hematopoiesis (31). Since extramedullary hematopoiesis occurs in compensation to maintain near-normal peripheral blood cell levels in the face of the reduction in bone marrow stem cells, hematopoietic stem cells might have expanded in the liver after stimulation by HGF to compensate for the decrease of blood cells. We also showed that HGF treatment ameliorated hematological dysfunction and increased cellularity of the spleen, bone marrow, and thymus in mice with lethal GVHD. The improvement of hematopoietic function in this lethal GVHD model may have been an indirect result of the amelioration of GVHD. However, HGF treatment also induced extramedullary hematopoiesis in the spleen and liver and promoted the recovery of peripheral blood cells in a syngeneic BMT model. These results strongly suggested that HGF treatment could promote hematopoiesis independently of its effect on GVHD after BMT.

Therapeutic strategies for the treatment of GVHD have been examined using animal models. These approaches include: (a) induction of donor T-cell tol- erance to host alloantigens by costimulatory blockade (32); (b) inhibition of coupling between extracellular death factors (such as FasL and TNF- $\alpha$ ) and their receptors using mAb's (24); (c) polarization of donor $\mathrm{T}$ cells from Th1 to Th2 using neutralizing Ab's against IL-12 (27) or cytokines such as IL-11 (33); and (d) protection of the GI tract from GVHD-mediated injury using pharmacological agents such as keratinocyte growth factor (34). Here we have described a new approach to the treatment of GVHD using HGF. We used transgene approach instead of recombinant protein for the following reasons: (a) since half life of recombinant protein is quite short, recombinant protein treatment needs an enormous dose of the active form of HGF protein and frequent injections; (b) administered high dose of the active form of HGF protein may cause adverse effects, such as tumorigenesis in other organs (35); (c) recombinant protein treatment is very costly. On the contrary, transgene approach is simple, safe, cheap, and needs much lessfrequent injections. Repeated injection of HGF-HVJ liposomes every week achieves continuous high-plasma HGF level (18). The present study obtained three major findings: (a) continuous production of HGF using the transgene approach provided effective protection against target-organ injury caused by acute GVHD, thereby improving the survival rate of GVHD mice; (b) HGF gene transfer increased extramedullary hematopoiesis by donor cells in the spleen and the liver, thereby promoting hematopoietic function after BMT; (c) the expression of IL-12, IFN- $\gamma$, and TNF- $\alpha$ in GVHD mice was suppressed by HGF. In summary, the present approach to the treatment of GVHD by HGF employs a different mechanism from those tested in previous studies. HGF may be useful for the treatment of patients with GVHD after BMT.

\section{Acknowledgments}

We thank K. Saheki for technical assistance. This work was supported by a Grant-in-Aid for Scientific Research provided by Ministry of Education, Science and Culture of Japan (No. 11671019).

1. Prentice, H.G., et al. 1984. Depletion of T lymphocytes in donor marrow prevents significant graft-versus-host disease in matched allogeneic leukemic marrow transplant recipients. Lancet. 1:472-475.

2. Thomas, E.D., et al. 1975. Bone marrow transplantation. N. Engl. J. Med. 292:832-843

3. Deeg, H.J., and Storb, R. 1984. Graft-versus-host disease: pathophysiological and clinical aspects. Annu. Rev. Med. 35:11-24.

4. Ferrara, J.L.M., and Deeg, H.J. 1991. Graft-versus-host disease. N. Engl.J Med. 324:667-674.

5. Martin, P.J., et al. 1985. Effects of in vivo depletion of T cells in HLAidentical allogeneic marrow grafts. Blood. 66:664-672.

6. Hill, G.R., et al. 1997. Total body irradiation and acute graft-versus-host disease: the role of gastrointestinal damage and inflammatory cytokines. Blood. 90:3204-3213.

7. Crawford, J.M. 1997. Graft-versus-host disease of the liver. In Graft-versus-host disease. 2nd edition. J.L.M. Ferrara, H.J. Deeg, and S.J. Burakoff, editors. Marcel Dekker. New York, New York, USA. 315-336.

8. Nakamura, T., Nawa, K., and Ichihara, A. 1984. Partial purification and characterization of hepatocyte growth factor from serum of hepatectomized rats. Biochem. Biophys. Res. Commun. 122:1450-1459.

9. Nakamura, T., et al. 1989. Molecular cloning and expression of human hepatocyte growth factor. Nature. 342:440-443. 
10. Kawaida, K., Matsumoto, K., Shimazu, H., and Nakamura, T. 1994 Hepatocyte growth factor prevents acute renal failure and accelerates renal regeneration in mice. Proc. Natl. Acad. Sci. USA. 91:4357-4361.

11. Ohmichi, H., Matsumoto, K., and Nakamura, T. 1996. In vivo mitogenic action of HGF on lung epithelial cells: pulmotrophic role in lung regeneration. Am. J. Physiol. 14:L1031-L1039.

12. Kato, Y., Yu, D., Lukish, J.R., and Schwartz, M.Z. 1997. Influence of luminar hepatocyte growth factor on small intestine mucosa in vivo. J. Surg. Res. 71:49-53.

13. Bardelli, A., et al. 1996. HGF receptor associates with anti-apoptotic protein BAG-1 and prevents cell death. EMBOJ. 15:6205-6212.

14. Kmiecik, T.E., Keller, J.R., Rosen, E., and Vande Woude, G.F. 1992. Hepatocyte growth factor is a synergistic factor for the growth of hematopoietic progenitor cells. Blood. 80:2454-2457.

15. Matsuda, Y., Matsumoto, K., Ichida, T., and Nakamura, T. 1995. Hepatocyte growth factor prevents liver cirrhosis caused by dimethylnitrosamine in rats. J. Biochem. 118:643-649.

16. Hakim, F.T., Sharrow, S.O., Payne, S., and Shearer, G.M. 1991. Repopulation of host lymphohematopoietic system by donor cells during graftversus-host reaction in unirradiated adult $\mathrm{F} 1$ mice injected with parental lymphocytes. J. Immunol. 146:2108-2115.

17. Morishita, R., et al. 1997. In vivo transfection of cis element "decoy" against nuclear factor- $\mathrm{\kappa B}$ binding site prevents myocardial infarction. Nat. Med. 3:894-899.

18. Ueki, T., et al. 1999. Hepatocyte growth factor gene therapy of liver cirrhosis in rats. Nat. Med. 5:226-230.

19. Gavrieli, Y., Sherman, Y., and Ben-Sasson, S.A. 1992. Identification of programmed cell death in situ via specific labelling of nuclear DNA fragmentation. J. Cell. Biol. 119:493-501.

20. Hashimoto, W., et al. 1995. Cytotoxic NK1.1 $\mathrm{Ag}^{+} \alpha \beta T$ cells with intermediate TCR induced in the liver of mice by IL-12. J. Immunol. 154:4333-4340.

21. Zarnegar, R., and Michalopoulos, G.K. 1995. The many faces of hepatocyte growth factor: from hepatopoiesis to hematopoiesis. J. Cell. Biol. 129:1177-1180.

22. Stuber, E., Freier, A.V., Marinescu, D., and Folsch, U.R. 1998. Involvement of OX40-OX40L interactions in the intestinal manifestations of murine acute graft-versus-host disease. Gastroenterology. 115:1205-1215.

23. Shulman, H.M., Sharma, P., Amos, D., Fenster, L.F., and McDonald, G.B.
1988. A coded histologic study of hepatic graft-versus-host disease after human bone marrow transplantation. Hepatology. 8:463-470.

24. Hattori, K., et al. 1998. Differential effects of anti-Fas ligand and antitumor necrosis factor- $\alpha$ antibodies on acute graft-versus-host disease pathologies. Blood. 91:4051-4055.

25. Brunda, M.J. 1994. Interleukin-12. J. Leukoc. Biol. 55:280-288.

26. Nestel, F.P., Price, K.S., Seemayer, T.A., and Lapp, W.S. 1992. Macrophage priming and lipopolysaccharide-triggered release of tumor necrosis factor alpha during graft-versus-host disease. J. Exp. Med. 175:405-413.

27. Williamson, E., Garside, P., Bradley, J.A., More, I.A.R., and Mowat, A.M. 1997. Neutralizing IL-12 during induction of murine acute graft-versushost disease polarizes the cytokine profile toward a Th2-type alloimmune response and confers long-term protection from disease. $J$. Immunol. 159:1208-1215.

28. Gazzinelli, R.T., Hieny, S., Wynn, T.A., Wolf, S., and Sher, A. 1993. Interleukin-12 is required for the T-lymphocyte-independent induction of interferon- $\gamma$ by an intracellular parasite and induces resistance in T-celldeficient hosts. Proc. Natl. Acad. Sci. USA. 90:6115-6119.

29. Hill, G.R., et al. 2000. The p55 TNF- $\alpha$ receptor plays a critical role in T cell alloreactivity. J. Immunol. 164:656-663.

30. van Dijken, P.J., Wimperis, J., Crawford, J.M., and Ferrara, J.L.M. 1991. Effect of graft-versus-host disease on hematopoiesis after bone marrow transplantation in mice. Blood. 78:2773-2779.

31. Taniguchi, H., Toyoshima, T., Fukao, K., and Nakauchi, H. 1996. Presence of hematopoietic stem cells in the adult liver. Nat. Med. 2:198-203.

32. Blazar, B.R., Taylor, P.A., Noelle, R.J., and Vallera, D.A. 1998. CD4(+) T cells tolerized ex vivo to host alloantigen by anti-CD40 ligand (CD40L:CD154) antibody lose their graft-versus-host disease lethality capacity but retain nominal antigen responses. J. Clin. Invest. 102:473-482.

33. Hill, G.R., et al. 1998. Interleukin-11 promotes $\mathrm{T}$ cell polarization and prevents acute graft-versus-host disease after allogeneic bone marrow transplantation. J. Clin. Invest.102:115-123.

34. Krijanovski, O.I., et al. 1999. Keratinocyte growth factor separates graftversus-leukemia effects from graft-versus-host disease. Blood. 94:825-831.

35. Takayama, H., et al. 1997. Diverse tumorigenesis associated with aberrant development in mice overexpressing hepatocyte growth factor/scatter factor. Proc. Natl. Acad. Sci. USA. 94:701-706. 